\title{
Dispersion Modelling in the Western Cape using the Model Ready Data Sets
}

\author{
Michael J. Weston ${ }^{* 1}$, Theo E. Fischer ${ }^{1}$, Angie L. Sanchez ${ }^{1}$ and Emmanuel Z. Tshuma ${ }^{1}$ \\ 1 ESCIENCE Associates (Pty) Ltd, 9 Victoria Rd, Oaklands, Johannesburg, 2192, South Africa, \\ michael@escience.co.za \\ ${ }^{1}$ Post Office Box 2950, Saxonwold, South Africa, 2132
}

\section{Introduction}

Results from air pollution dispersion modelling that was conducted as part of a health risk assessment in the Western Cape is presented in this paper. Modelling was conducted using the Calpuff dispersion model and utilised the meteorological model ready data sets available from the Western Cape Government Department of Environmental Affairs and Development Planning.

\section{Aims and Objectives}

The following questions are answered in this study:

- Does the use of a regional domain produce higher concentrations due to simulation of "recirculation"?

- Do the smaller, non-scheduled sources warrant use in a dispersion model for air quality applications?

\section{Methodology}

\subsection{Model Domains}

We run the Calpuff dispersion model (Scire et al. 2000) for scheduled and non-scheduled emitters in the Western Cape. Two model domains are used; a regional domain with a $2 \mathrm{~km}(270 \times 325 \mathrm{~km})$ resolution and a smaller local domain covering the city of Cape Town with a $300 \mathrm{~m}$ resolution $(50 \times 50 \mathrm{~km})$.

\subsection{Sources Modelled}

APPA industrial sources were modelled in the City of Cape Town domain and the same sources were modelled in the regional domain. This will help identify whether average concentrations are higher in the regional domain due to a longer life time of puffs and, therefore, the chance for recirculation.

Non-scheduled sources were modelled in the $300 \mathrm{~m}$ City of Cape Town domain (hereafter referred to as local domain) to quantify the contribution of these numerous smaller sources to the atmosphere. These sources were not modelled in the regional domain because they have short stacks and are expected to have an effect on immediate surroundings and not on a regional scale.

\section{Preliminary Results}

\subsection{Predominant Wind Direction}

Cape Town experiences two predominant wind directions, namely the South-Easter and NorthWesterly flow (Figure 1). Wind flow shifts between these two directions during the day, thus allowing for events where emissions from a source are blown away from the source at one time of the day and blown back later in the day.

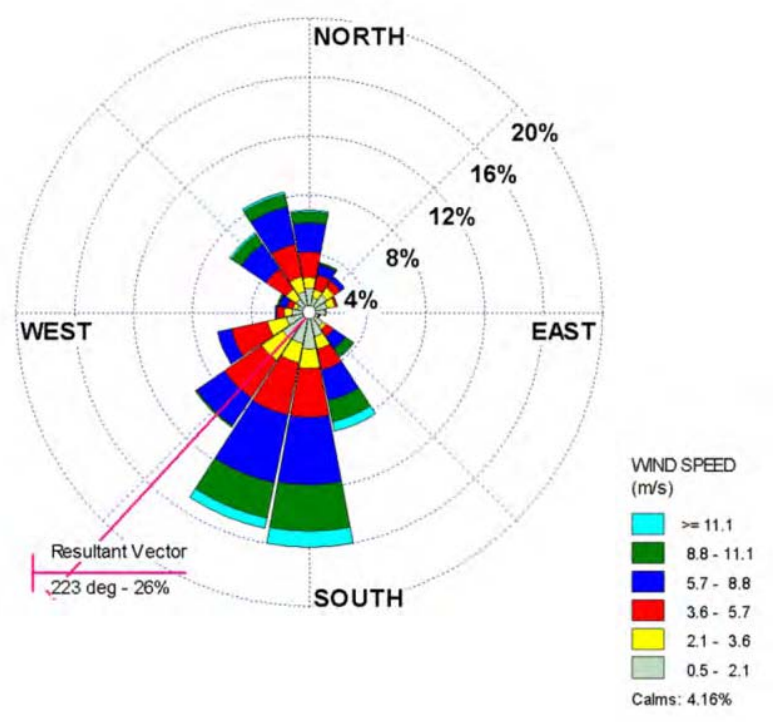

Figure 1. Annual (2010) windrose at Cape Town International Airport.

\subsection{Scheduled Sources}

Annual average concentration of $\mathrm{SO}_{2}$ from scheduled sources was low and ranged from 0.5 to $18 \mathrm{ug} / \mathrm{m}^{3}$. In general, results from the local domain (Figure 2) produced similar magnitude and spatial distribution of annual concentrations of $\mathrm{SO}_{2}$ than results from the regional domain (Figure 3 ). This suggests that the smaller $50 \times 50 \mathrm{~km}$ domain adequately captures any return flow and is not bias to under prediction caused by puffs exiting the model domain.

Neither domain demonstrated a bias in simulating higher concentrations when considering maximum 1 hour averaged concentrations. Instead, this varied on a source by source basis. In general, the local domain produced higher 1 hour concentrations for high emitters, and thus, overall, when all emitters are considered together, produced higher maximum 1 hour concentrations.

\subsection{Non-scheduled Sources}

Annual average concentration of $\mathrm{SO}_{2}$ from small industries was in the same range as scheduled sources. However, as expected, the geographic extent of concentrations above $5 \mathrm{ug} / \mathrm{m}^{3}$ is much smaller (Figure 4). 


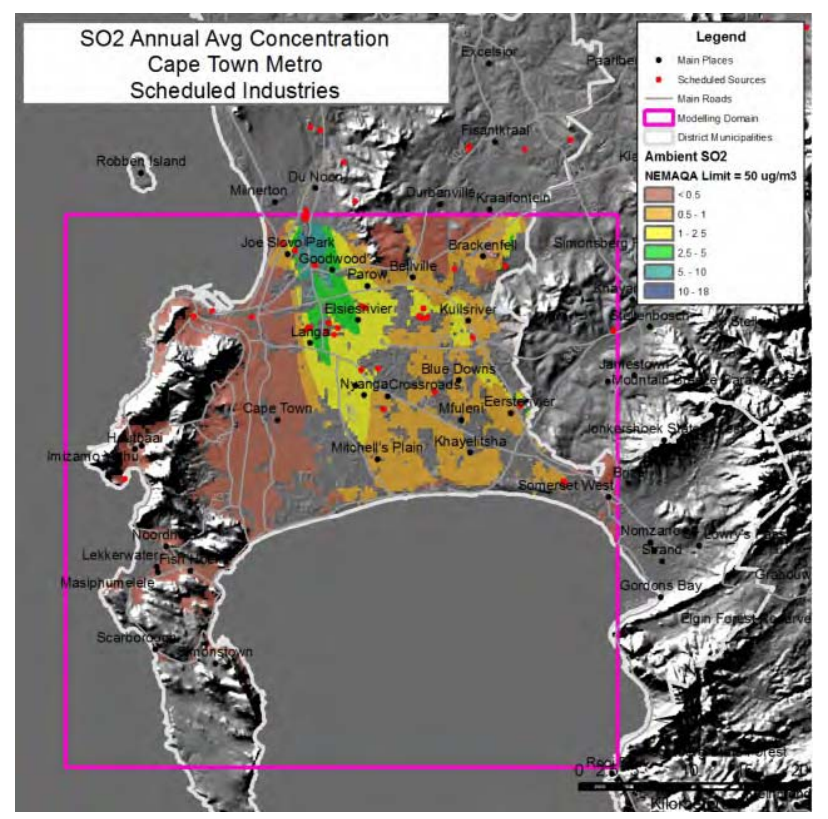

Figure 2. Annual $\mathrm{SO}_{2}$ concentrations from scheduled sources in the local domain.

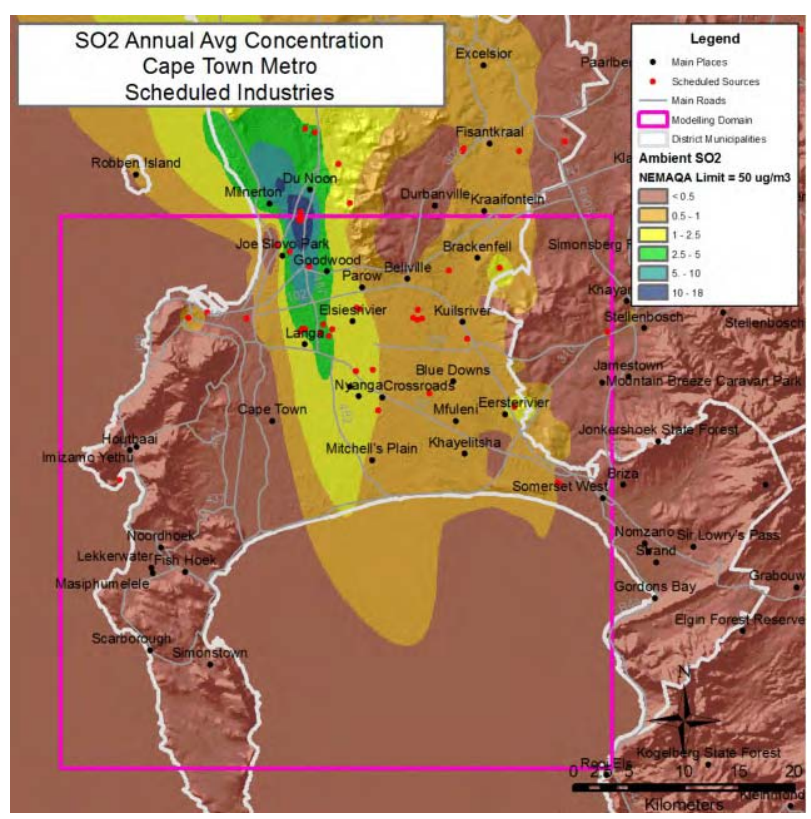

Figure 3. Annual $\mathrm{SO}_{2}$ concentrations from scheduled sources in the regional domain.

The contribution of small industries to the annual average $\mathrm{SO}_{2}$ concentration is particularly high (above $50 \%$ ), for the Southern suburbs and extending to Muizenberg (Figure 6). However, concentrations are very low in these areas and can be considered negligible. Of much more interest is the area around Belville South (black circle in Figure 5 and Figure 6) where annual concentrations are higher (5) and small industries contribute $50 \%$ or more in some places (6). This suggests that small industries can be a substantial contributor to air quality, although concentrations are low.

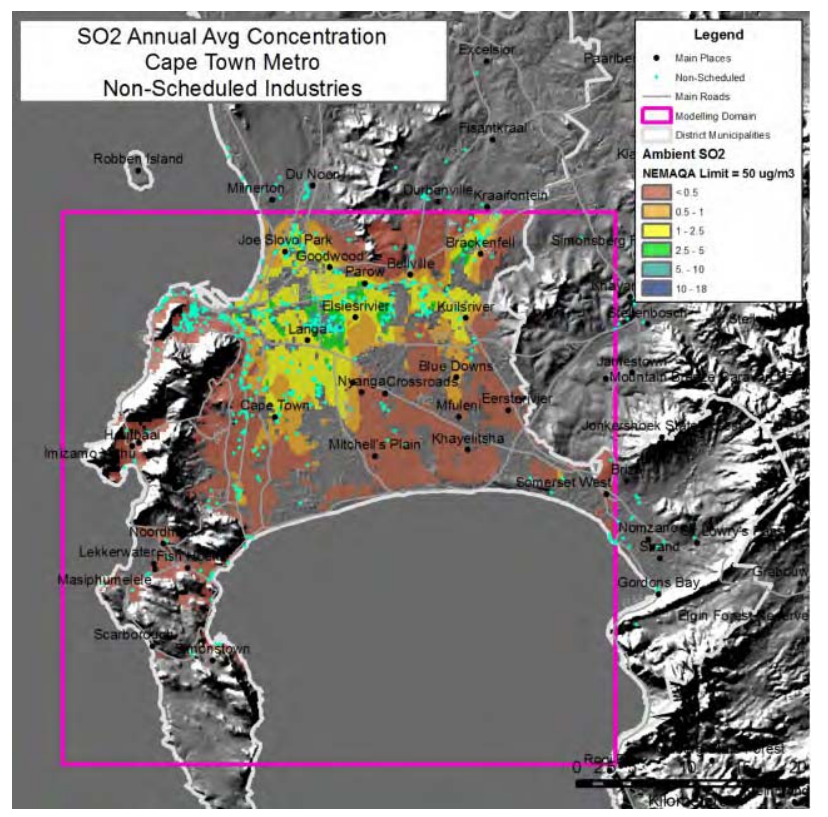

Figure 4. Annual $\mathrm{SO}_{2}$ concentrations from nonscheduled sources in the local domain.

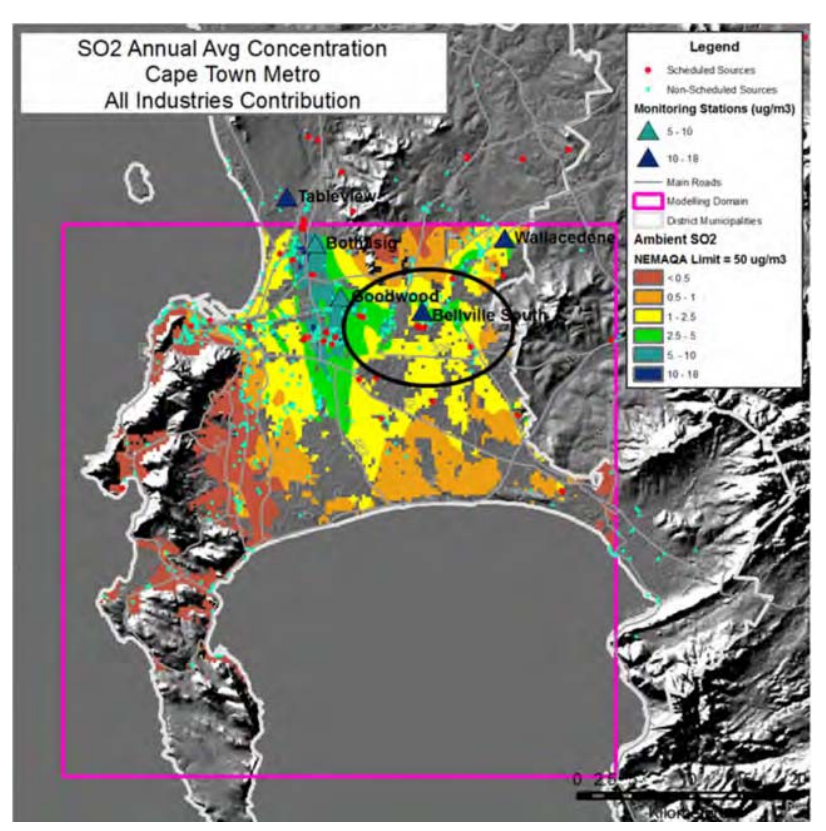

Figure 5. Total annual $\mathrm{SO}_{2}$ concentrations from scheduled and non-scheduled sources in the local domain.

Figure 6 on next page.

\section{Conclusions}

Modelling dispersion using smaller, non-regional domains produced similar results to regional domains. This suggests that the local domains adequately captured any return flow.

Small industries produce low annual concentrations (between 1 and $2.5 \mathrm{ug} / \mathrm{m}^{3}$ ). However, small industries contribute over $50 \%$ of the annual concentration for 
some areas when combined with scheduled sources.

\section{Acknowledgments}

The authors wish to acknowledge the Department of Environmental Affairs and Development Planning (DEA\&DP) of the Western Cape Government for funding this work in part and for supplying information on small industry emissions in Cape Town.

\section{References}

Scire J., Strimaitis, D., and Yamartino, R, 2000, CALPUFF Dispersion Model, Earth Tech, Inc., U.S.A.

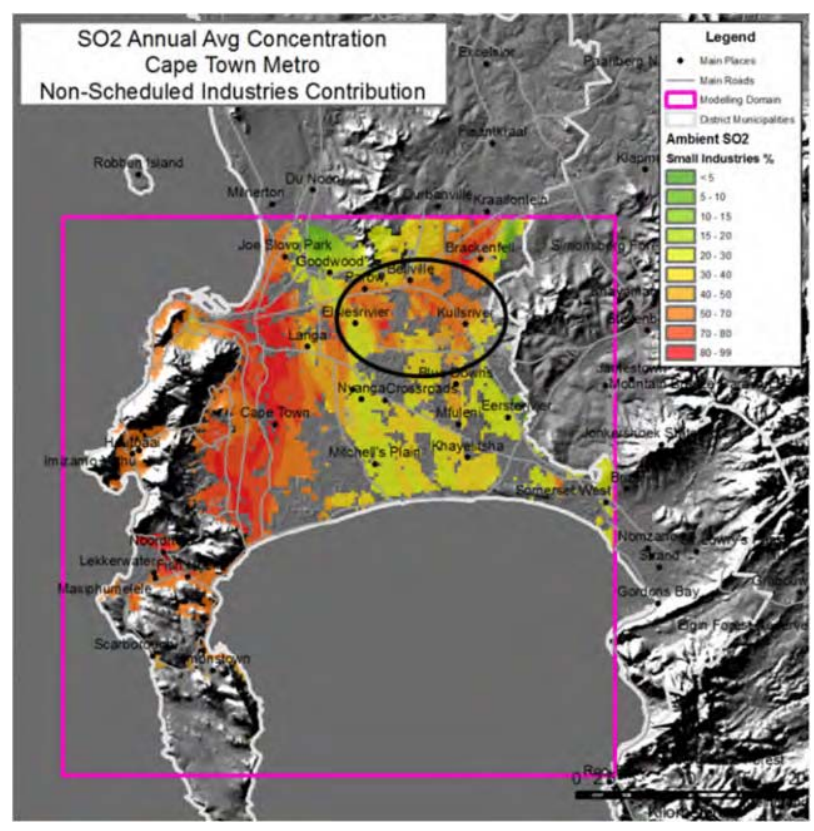

Figure 6. Percent contribution of small industries to annual $\mathrm{SO}_{2}$ concentrations combined with scheduled sources. 